\title{
Assisted Learning Virtual Support (ALVS) for Personal Learning Environments
}

\author{
Robert Costello, Nigel Shaw \\ Graduate School, University of Hull
}

\begin{abstract}
In this paper, we propose how to use the ALVS to support a more dynamic Personal Learning Environment (PLE) within the Graduate Virtual Research Environment (GVRE). The virtual support will provide a 24 hour answering servicing for postgraduate students relating to their PhD journeys, for example, advice needed regarding "how to carry out a literature review". The ALVS found within the GVRE will use a rule base to retrieve, text based, a repository of videos (280), and features from web sources through the PLE and relate them to the frequently asked question. This approach of blending videos, web-sources, presentations, and text to the student questions should enhance and accelerate Self-Regulated Learning (SRL).
\end{abstract}

\section{Introduction}

The GVRE was tailored and co-created by research students, making it more engaging and personalised [1]. The GVRE provides the research students with visual and navigational aids to assist them in a friendlier HCI environment [2] [3]. The HCI environment is structured around the Researcher Development Framework (RDF) and the Joint Skills Statement by providing a means for which individual students may learn from more experienced researchers [4] [5].

\section{Motivation for Assisted Learning within the GVRE}

Sandars and Schroter suggest that the need for supporting postgraduates is vital due to issues relating to barriers of technologies, diversity of learning preferences and quality of resources [6]. According to Littleton and Whitelock the notion of learning online should be emphasized through understanding the processes involved in the "creation of meaning, knowledge and understanding" [7]. Bullen and Kenway and Brown indicate that due to the diverse nature of postgraduate learners, students will face different expectations and culture shocks, for example: "Philippine way of learning, which was to question and then provide a solution", "in which 'lecturers tell everything in detail" and students "get help directly', rather than work things out by themselves" [8] [9].
This approach is slightly different from UK universities as more emphasis is put on independent learning [10]. As suggested by Bullen and Adam to support a cross-section of postgraduate learners Universities must provide academic support that encourages self-learning and encourages motivation [8] [10]. Adam indicates that postgraduate students for whom English is not their native language will struggle from lack of confidence in a variety of different areas associated with a $\mathrm{PhD}$. Brown builds upon the issues that Bullen and Adam indicates by saying that international students find it difficult when relating to "poor reading, writing skills and finding ways of expressing themselves" [8] [9] [10].

This can lead to the postgraduate students having "emotional reactions of embarrassment, impotence, shame, anxiety and frustration". To tackle these issues that were mentioned by [8] [9] 10]; literature within the area of personalized learning can be used to provide an effective way to support and improve postgraduates through the use of interaction and rich media activities [3] [11] [12] [13].

The main contribution of our work focuses on using an Assisted Learning-Virtual Support (ALVS) mechanism, to enable students to use a rule base to query questions that are commonly associated with their $\mathrm{PhD}$ and a filtering search to retrieve and integrate Videos/Web-sites and interactive rich media activities found within in the GVRE repository [3] [11] [12] [13]. The personalized approached taken by the GVRE supports a variety resources; however, does not tailor all the needs like, using external web-based platforms to maximum retrieval of reusability educational materials, PowerPoint presentations and other internet applications. The new approach adopted here will focus on bringing together external resources enabling students to have more support for Self-Regulated Learning, and community grouping. This approach will enable postgraduates to have additional support with rich media embedded into their learning 24 hours a day.

\section{Personal Research Environments}

PLE's are used to enable students to take ownership over their own learning, through a multitude of webbased applications and platforms. PLE's according to Sclater must comprise of "a piece of coordinating software seen by the learner that interacts through webservices within a variety of educational tools and data 
sources" in existing platform architecture. Sclater suggests that current Learning Management Systems like that of Blackboard, Moodle, Ebridge, are controlling the educational creativity of the individuals and that PLE's are the new way to embrace learner centricity through tools hosted from outside the institutions [14].

According to Nussbaumer et al., PLE's will enable individuals to building and develop their own learning and monitoring paths through reflection [15]. Nussbaumer et al., agrees with Skiba and Sclater about bring individuality learning through the use of meta-cognition development within a PLE environment [14] [15][16]. PLE, through the use of Self-Regulated Learning (SRL) tasks via aid of web 2.0 platforms like that of Twitter, Facebook, YouTube, and www.Slideshare.net, will encourage learners to engage informal learning to "pursue educational goals" [15].

Nicol and Macfarlane-Dick, Nicol suggests that students who uses SRL, automatically engages, in thinking, motivation and accommodate their behavior to the learning activity [17]. "In practice, selfregulation is manifested in the active monitoring and regulation of a number of different learning processes, e.g. the setting of, and orientation towards, learning goals; the strategies used to achieve goals; the management of resources; the effort exerted; reactions to external feedback; the products produced." [17].

Henter and Unianu indicates that PLE's can fit into two categories when designing techniques for efficient, effective learning and teaching methods for the use of web 2.0 platforms, these can be Metacognition and Metacognitive [18].

Metacognition: - refers to reflective learning. According to Webster, R., "concerning the potential role of reflective learning" [19]. Meyer et al., indicate that the key features to Metacognition are that the student has an awareness of knowledge and can control their own learning stimulus [20].

Metacognitive: - "involves Planning, monitoring, testing, revising, and assessing the strategies used for learning" and also "Prediction, problem solving and listening to others" [20]. The use of PLE's within an informal learning situation while using web-based platforms can create a customized learning environment, tailored to a variety of learners needs. This can support interoperability through multimedia, open standards, and reusability's of curriculum materials.

"Technology is ubiquitous, embracing almost every part of our lives, our communities, and our homes. In the field of education, technology doesn't have a secondary role in the sole process of knowledge transferring, especially because technology is becoming increasingly integrated into the lives of learners of all age groups" [21].

The ALVS will harness the concepts of the PLE's capabilities by pulling in PowerPoint Presentations belonging another web-based repository and web- based platform called www.Slideshare.net. The ALVS will store key theme PowerPoint's, Open Office Documents or
PDF links relating to postgraduates studies, which once clicked will enable the student to be redirected to another service for educational purposes.

\section{Research Approach}

The research approach adopted within this paper is to investigate whether an Assisted Learning- Virtual Support (ALVS) mechanism can bring additional support to postgraduates through providing a generic question and answering facility to the GVRE. To monitor the ALVS we used the built-in features found within E-bridge (Sakai) Site Stats (Activity, and Resources). At first used a preliminary sample group of 30 that tested the first ALVS feature allowing it to go live.

The preliminary findings indicated that the current features of the rule-based knowledge system did provide support; however, it was not adequate and lacked a wealth of learning activities. However, a mixed method approach was then used to help us to explore and analyse the next generation step. This step refers to the development of the PLE's features, which is currently being investigated and researched.

\section{Assisted Learning-Virtual Support}

The Assisted Learning-Virtual Support Mechanism was influenced from the work carried out by [22] by extracting sentences and keywords; [22] Enhancing cyber classrooms through sharing files, videos, and interactions through tasks;[24] using e-learning to provide Critical Thinking through Instructions, Hints and feedback; [25] Adaptive Intelligent Personalised Learning to improve online learning;[26,27] a new recommender system to suggest learner materials for on-line studies; [28]

WebLearn which uses a Question and Answering system for undergraduates.

The ALVS has five main areas,

1.1 The rule base,

1.2 The filtering mechanism - text based reply

1.3 Video reply SoftSearch

1.4 Video reply ALVS

1.5 PLE Features (PowerPoint, OpenOffice, and PDF)

\subsection{Rule Base}

The prototype belonging to the ALVS will have a two phase development cycle associated with it. Phase one is the development of how the individual request is going to processed by the ALVS [22] [25] [28]. Is the user input going to extracted and processed through keywords or by processing whole sentences, which is similar to WebLearn Q\&A system, for undergraduates [22] [25] [28].

Phase two will focus on implementing a variety of Information Retrieval methods linked to the Question and Answer Rule Base repository [23] [24] [27] [28]. More information upon this phrase can be found within 
the Filtering Mechanism section B.

The first method that was introduced into the ALVS was linking and comparing sentences that a postgraduate student would input relating to their studies [22] [28]. To reduce zero feedback on the original question, a keyword algorithm will search through the sentence and extract and compare highlighted words that are already developed into a previous softsearch engine, found within the GVRE [3]. To demonstrate this feature, please see Fig 1, two phase extraction procedure.

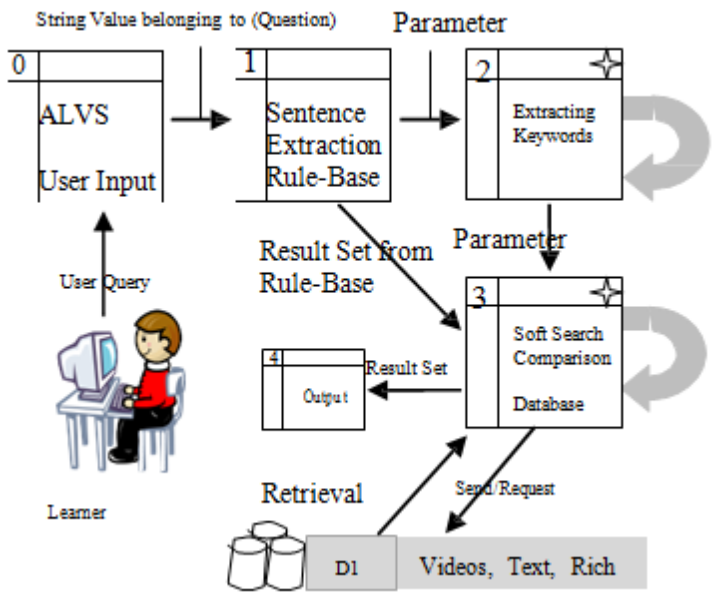

Figure 1. Two phase extraction procedure

\subsection{Filtering Mechanism (Text \& Video)}

The filtering mechanism uses a soft search scripting technique to retrieve and filter videos that are held within an external web 2.0 platform. The videos' web-addresses, descriptions are stored and located within a data source to enable the softsearch to filter and match keywords before retrieval. The filtering mechanism is written using internet technologies that are supported within E-bridge. These are Ajax, and JavaScript; however, $\mathrm{PhP}$ and PostgreSQL are also used to store additional features.

The ALVS can be represented using a Venn diagram

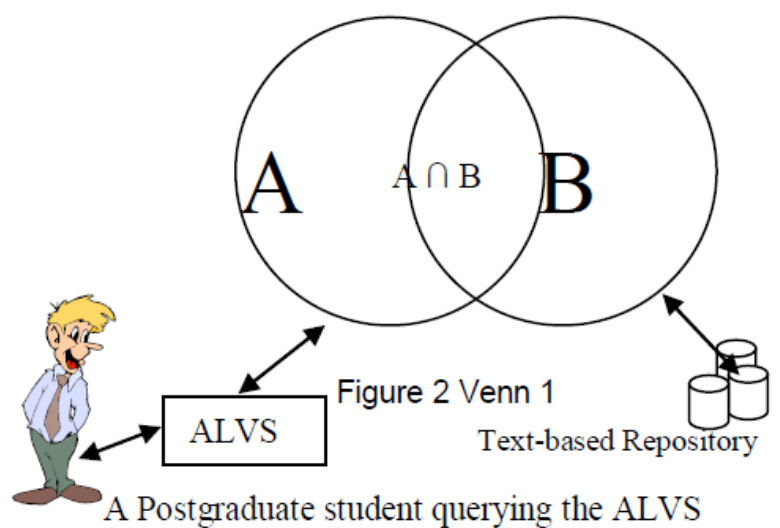

Case study example:
A first year $\mathrm{PhD}$ student is seeking information relating to his upgrade report. He types into the ALVS "What is required for my upgrade report?" The rulebase would search firstly: text based answers, which can be seen in Fig 2 (Venn 1) Secondly the search would then interrogate the video repository relating to 6 month review, which can be seen in Fig 3. (Venn diagram $2-$ Search categories)

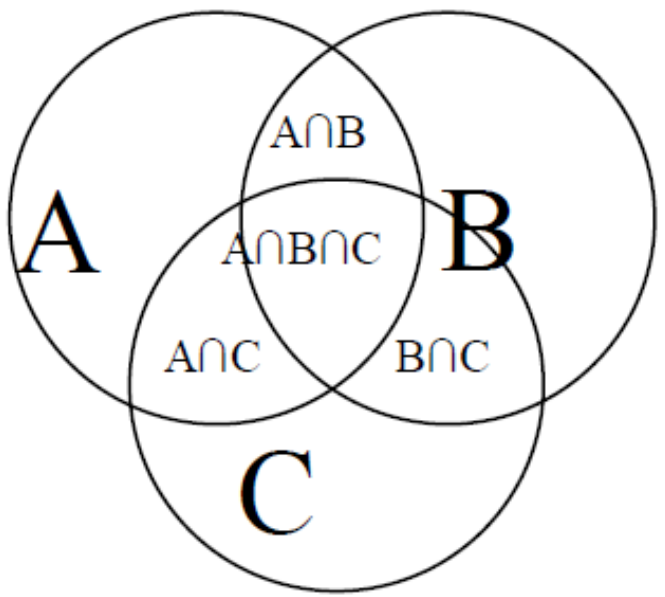

The search belonging to the ALVS within the GVRE would be able to use the intersection of:

$A \cap B$, To interrogate rule base for text base answer within a knowledge pool located within webserver.

$\mathrm{A} \cap \mathrm{B} \cap \mathrm{C}$, At the same time, the search will be filtering the videos within the repository to see if any matches can be retrieved.

$A \cap \mathrm{C}$, The Rule-Base will search the video knowledge base independently if the text base answer comes back negative and this will also send a request to the developer (or admin to add content if the question could not be answered on-line) making sure that the individual request is flagged up and dealt with - this acting as a failsafe mechanism.

$\mathrm{B} \cap \mathrm{C}, \mathrm{B}$ intersection of $\mathrm{C}$ is used to create a SoftSearch match between keywords associated with text and video (this will be achieved through descriptive text).

\subsection{Video reply SoftSearch}

Currently the Softsearch information retrieval (IR) mechanism used within the GVRE displays information about videos using descriptive information and providing a link directly to the video. ALVS interconnects with the SoftSearch to filter and retrieve videos held within a repository.

\subsection{Video reply ALVS}

The ALVS will allow postgraduate students to enter a particular question associated with their degree and the rule-base, which interrogates a repository of videos and supportive materials to find a suitable answer. If an answer is not found then the question will be forwarded to the developer to allow it to be built into the Rulebase for future development. Please see Fig 4, for a visual representation of the ALVS mechanism currently being developed within the GVRE environment. 


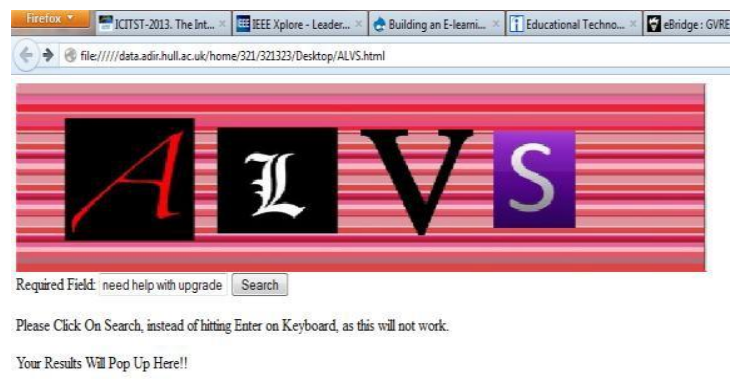

Figure 4. ALVS Visual Representation

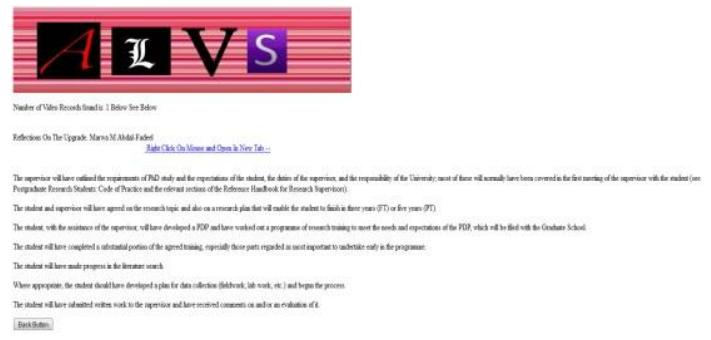

Figure 4. ALVS Visual Representation

\subsection{PLE Features (PowerPoint, OpenOffice, and PDF)}

The PLE's features found within the advancements to the ALVS Q\&A architecture, will hopefully improve the overall educational experience. However, this can only be achieved by individually supporting the needs of postgraduates within an out hour response service. This out hour response service must take into consideration of learning activities, the educational experience, individuality, and self-regulated learning (SRL).

5.5.1 Out-hour Learning Activities. The Activities are used and stored within external web-based platforms like that off Facebook, and Twitter, YouTube and www.Slideshare.net. The ALVS will have additional links with details describing; - how to access them, short description (visual, graphical, audio, text) what type of learning style is associated with the task. Each activity, will deal with different topics relating to the question asked within the rule base. Each web-based platform, will use different features to activity engage the individuals for example:

According to Grosseck, and Holotescu (2008)

[29] "Twitter can be used to communicate, to ask questions, to ask for directions, support, advice, and to validate open-ended interpretations or ideas by discussing with the others. Twitter has mashed up personal publishing and communication, the result being a new type of real-time publishing. " ([29] Page 2).

Benefits of using twitter within HE especially at postgraduate level is to create a virtual classroom community in which teams can formed to promote and develop academic writing skills. This approach enables students to keep a personal development of progress on line "record their cognitive trails" and this will enable them to submit work for their reflective dairies.
The ALVS will have a series links that will point research students to related questions belonging to the Q\&A to encourage extra curriculum activities. Twitter enables you to post web-links redirecting students to other guidance on topics expanding further; used for complex areas, or diagrams needed to support $\mathrm{PhD}$ research students. However, limitations of this approach can be: students being easily distracted from other web 2.0 applications and usages; lack of educational structure (not clearly thought out tasks designed by the course lecturer); privacy of thought and intellectual property; out of date support and guidance.

The other important web-based platform that the ALVS was interested in was the: www.Slideshare.net. Due to the limitations of the search and questions only bring back videos, text and web-sites, this was not enough for postgraduates and instead presentations were required, documents, and pdfs as additional learning materials to support them while there were on the go (using mobile, tablets, IPads, etc...). Please see Fig. 5 Layout of Slideshare.net.

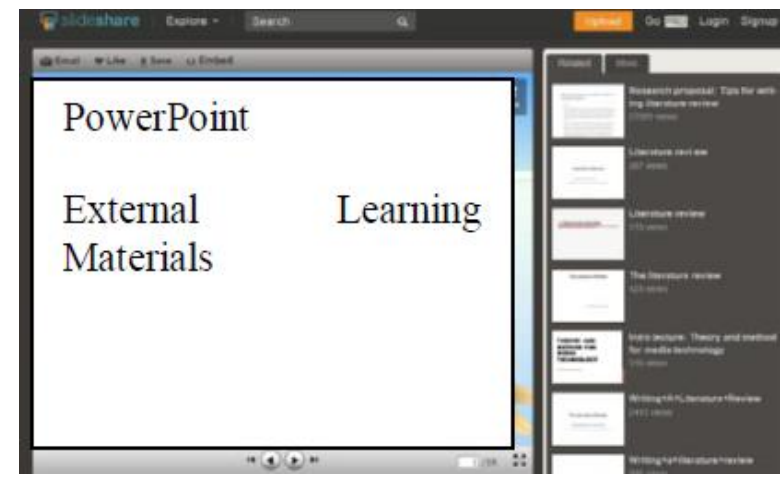

Figure 5: Layout of SlideShare.net

The course-designer or the developer of the ALVS would search for key terminologies within the SliderShare.net and place key links within the Q\&A search engine. When a particular topic or question is proposed the retrieval function will pick up key terminologies associated with PLE feature to retrieve the following:

Descriptive Tag: Array SS = "Slideshare", Description $=$ "Literature Review", LearningFeature = "PowerPoint", LearningStyle = "Visual";

ALVS will use this information to display detailed description about what is offered in direct relation to the question being asked by the student when they need help. For a graphical representation of what the information looks like, please see Fig 4.

\section{Conclusion}

In this paper, we are trying to explore and illustrate the design of trying to advance the features of the Assisted Learning-Virtual Support (ALVS) mechanism to support PLE's approaches within HEI's. Through incorporating web-based platforms like Facebook, twitter and SlideShare.net we can support those questions that maybe cannot be answered in normal working hours. The GVRE was designed to offer 24/7 support. The Question and 
Answering mechanism will enable the e-learning system to become more adaptable and flexible within the coming year to enable not just International, EU or home UK students to benefit but hopefully gives ideas into what is possible with new and existing technology are merge together.

\section{References}

[1] C., Thomson, and B. Allan., (2010). "Supporting the Learning and Networking Experiences of Doctoral Students" Proceedings of the 7th International Conference on Networked Learning, 2010

[2] R., Costello, N. Shaw, B. Allan, and D. Mundy., (2012). "The Development of an E-learning Environment to Enable a Personalised Learning Approach for Research Students" International Conference on Information Society (iSociety/IEEE June 25-28 2012)

[3] R., Costello, and N., Shaw., (2013). "The Development of a Blended Learning Experience to Enable a Personalised Learning Approach to Researcher Development for Research Students". The International Journal of Learning in Higher Education Volume 19, 2013, thelearner.com, ISSN 2327-7955 [4] Vitae., (2012). "Researcher Deverlopment Framework" http://www.vitae.ac.uk/CMS/files/upload/Vitae-RDFbriefing-Employers-2012.pdf (19 August 2013)

[5] Vitae., "Joint Skills Statement" (2012). http://www.vitae.ac.uk/policy-practice/1690/Joint-SkillsStatement.html (19 August 2013)

[6] J., Sandars, and S., Schroter,, (2007). "Web 2.0 technologies for undergraduate and postgraduate medical education: an online survey." Postgrad Medical Journal. 2007 December; 83(986): 759-762.

[7] K., Littleton, and D., Whitelock., (2005). The negotiation and co-constructions of meaning and understanding within a postgraduate online learning community. Learning, Media and Technology, 30(2), pp. 147-164

[8] E., Bullen, and J., Kenway, (2003). "Real or Imagined Women? Staff representations of international women postgraduate students", Discourse: Studies in the Cultural Politics of Education, 24: 1, 35 - 49

[9] L., Brown, (2008). "Language and anxiety: an ethnographic study of international postgraduate students". Evaluation \& Research in Education, 2008 - Taylor \& Francis [10] K., Adam., (2004). "Modelling success: enhancing international postgraduate research students' self-efficacy for research seminar presentations. Higher Education Research \& Development" Vol. 23, No. 2, May 2004, PP, 124 - 130

[11] M., H., Selim, (2007). Critical Success factors for elearning acceptance:

Conwrmatory factor models. Computers \& Education 49 (2007) pp. 396-413

[12] C., Conzalez., (2008). "Conceptions of, and approaches to, teaching online: a study of lecturers teaching postgraduate distance courses" High Educ (2009) 57::299-314

[13] M., Flammia, Y. Cleary, D. M., Slattery., (2010)., "Leadership Roles, Socioemotional Communication Strategies, and Technology Use of Irish and US students in Virtual Teams" IEEE Trascations on professional communciation, Vol. 53, No 2, June 2010

[14] N., Sclater, (2008). "Web 2.0, Personal Learning Environments, and the Future of Learning Management Systems". Educause Center for Applied Research, Volume 2008, Issue 13, June 24, 2008.

[15] A., Nussbaumer, M., Kravcik, and D., ALbert (2012) "Supporting Self-Reection in Personal Learning Environments Through User Feedback."

Vol, 872. http://ceur-ws.org/Vol 872/pale2012_paper_7.pdf

[16] D, J. Skiba. (2008) "Can you post a Nugget of
Knowledge in 140 Characters or Less?" Emerging Technologies Center, Nursing Education 2.0: Twitter \& Tweets. Nursing Education Perspectives 2008 Vol.29 No.2 Pages 110-112

[17] D., J. Nicol, and D., Macfarlane-Dick, (2006) "Formative assessment and self-regulated learning: a model and seven principles of good feedback practice".Studies in Higher Education. Vol. 31, No. 2, April 2006, pp. 199-218

[18] R., Webster, (2013). "Metacognition and the Autonomous Learner: Student Reflections on Congnitive Profiles and Learning Environment Development"

http://citeseerx.ist.psu.edu/viewdoc/download?doi=10.1.1.85.400

7\&rep=rep1\&type $=$ pdf $(10$ January 2014)

[19] E., Meyer, P., C. A. Abrami Wade., O., Aslan, and L., Deault, (2009)

"Improving literacy and metacognition with electronic portfolios: Teaching and learning with ePearl"

http://digitalcommons.calpoly.edu/cgi/viewcontent.cgi?article=1 006\&context=coe_dean (20 Decemeber 2013).

[20] N., Petrovic, D., Petrovic and V., Jeremic, (2012) "Possible Educational Use of Facebook in High Environmental Education" (2012) ICICTE $2012 \quad$ Proceedings 355 http://www.icicte.org/Proceedings2012/Papers/09-1-Petrovic.pdf [21] Y., Haga, and M., Arai., (2008). A Method to Extract Sentences Referenced by students' technical reports using parse trees and word concepts. icalt, pp.82-84, 2008 Eighth IEEE International Conference on Advanced Learning Technologies, 2008

[22] N-S., Chen, Y., Wang, P-J., Wu, and M., Levy., (2008) Developing a pedagogically meaningful e-tutor training program for cyber face-to-face language teaching. Icalt, pp. 361-364 Eighth IEEE International Conference on Advanced Learning Technologies, 2008

[23] I., Cheng, and N., Rossol., (2008). Self-tutoring, Teaching and Testing: An Intelligent Process Analyzer. Icalt, pp. 746-750, 2008, Eighth IEEE International Conference on Advanced Learning Technologies, 2008

[24] R., Costello, D.P., Mundy., (2009). "The Adaptive Intelligent Personalised Learning Environment," ICALT, pp.606610, 2009 Ninth IEEE International Conference on Advanced Learning Technologies, 2009

[25] K., I, Ghauth, and N., A., Abdullah, (2009). "Building an ELearning Recommender System using Vector Space Model and Good Learners Average Rating". Icalt, pp.194-196 2009 Ninth IEEE International Conference on Advanced Learning Technologies

[26] K., I. Ghauth, and N., A. Abdullah., (2010). Measuring learner's performance in e-learning recommender systems. Australasian Journal of Educational Technology, 26(6), 764-774 [28] Q., Dang, T., Wang, and P., Pan., (2013). An Intelligent Agent to Assist Student Learning Introductory Programming. The Higher Education Academy STEM, pp 28 - 33, Learning Technologies June University of London Greenwich

[29] G., Grosseck, and Holotescu (2008). Can we use twitter for education activities? The 4th International Scientific Conference, eLearning and Software for Education. Bucharest, April 17-18, eLSe 2008. 